\title{
Development of monoclonal antibodies for detection of necrotizing hepatopancreatitis in penaeid shrimp
}

\author{
Deborah J. Bradley-Dunlop*, Carlos Pantoja, Donald V. Lightner
}

Department of Veterinary Science and Microbiology, University of Arizona, Tucson, Arizona 85721, USA

\begin{abstract}
Monoclonal antibodies (MAbs) were produced against necrotizing hepatopancreatitis bacteria (NHP-B) of penaeid shrimp. The MAbs tested in dot-immunoblot (D-IB) assays were capable of detecting the NHP-B in hepatopancreas samples collected from moribund juvenile Litopenaeus vannamei during an experimentally induced NHP-B infection. The MAbs were also screened by immunohistochemistry (IHC) using case submissions that were determined to be infected not only by histology, but also polymerase chain reaction (PCR) and in situ hybridization (ISH) assays using specific digoxigenin (DIG)-labeled probes on histological sections prepared from naturally infected shrimp. Two of the MAbs were chosen for development of detection methods for NHP. The MAbs were tested using IHC methods on Davidson's alcohol-formalin-acetic acid (AFA) fixed tissue sections and identified NHP-B infected cells and tissues in a pattern similar to that seen with DIGlabeled NHP-specific gene probes. None of the MAbs reacted with tissue from specific pathogen-free (SPF) shrimp or with shrimp tissues infected with a rickettsia-like bacteria, Vibrio sp., Campylobacter sp., and Spiroplasma sp. The MAbs were found to be negative against these other organisms, demonstrating that they are species specific and useful for rapid diagnostic detection of NHP-B.
\end{abstract}

KEY WORDS: NHP · Necrotizing hepatopanceatitis · Monoclonal antibodies · Dot-immunoblot · Immunohistochemistry

\section{INTRODUCTION}

The necrotizing hepatopancreatitis bacterium (NHPB) is a Gram-negative intracellular rickettsial-like bacterial disease which targets penaeid shrimp, infecting the tubular epithelial cells of the hepatopancreas (HP) (Loy et al. 1996). NHP was originally identified in 1990 in cultured Litopenaeus vannamei in Texas (USA) (Frelier et al. 1992). The disease has now been reported in several locations throughout the Western Hemisphere including Texas, Peru, Ecuador, Columbia, Venezuela, Brazil, Nicaragua, Panama, Costa Rica and Mexico (Loy et al. 1996, Aguirre-Guzmán \& Ascencio Valle 2000, Pantoja \& Lightner 2003). NHP can result in significant production losses, with mortalities ranging from 25 to $95 \%$ in affected ponds (Loy et al. 1996). Gross signs presented by shrimp with severe
NHP-B infection include lethargy, low growth, anorexia and an empty intestinal tract, soft shells, and flaccid bodies. Other indirect signs include blackened or darkened gills due to fouling, bacterial shell disease (cuticle lesions, melanization, appendage erosion), and expanded chromatophores (Aguirre-Guzman \& Ascencio Valle 2000). Once signs of NHP infection occur in ponds, the timing of diagnosis of the infection is critical, because while NHP can be treated with medicated feed, shrimp populations with a high prevalence of NHP can cease feeding, significantly reducing the efficiency of the medicated feed administered.

Currently, 3 methods are used for the detection of NHP: (1) routine histological analysis of specimens fixed in Davidson's alcohol-formalin-acetic acid (AFA) solution; (2) in situ hybridization (ISH) on fixed tissues with NHP-specific gene probes; and (3) polymerase 
chain reaction (PCR) using NHP-B specific oligonucleotide primers. The 3 methods require special laboratory equipment and highly trained personnel to carry out respective assays and interpret the results. Furthermore, each of these assays can take up to $2-3 \mathrm{~d}$ to produce the diagnostic result.

Monoclonal antibodies (MAbs) are used in many formats as diagnostic tools; they can be used in enzyme linked immunosorbent assay (ELISA), immunohistochemistry (IHC), dot-immunoblot (D-IB) assays, and lateral flow formats (Bangs Laboratories Tech Notes 1999) such as those currently used in home pregnancy test kits. These antibody-based methods are relatively rapid, requiring only a matter of minutes to hours to run, and they require less expertise and no special equipment other than the diagnostic methods that are currently being utilized in shrimp disease diagnostic laboratories. Another significant advantage to antibody-based diagnostics tests is that some are rapid, simple and can be used pond-side for immediate diagnosis. These characteristics make the use of MAbs as a diagnostic tool a practical addition to the available methods.

This study reports the production of MAbs to NHP-B infected tissue, and their application to several immunologic assay formats for use in diagnosis of the disease. This study also demonstrates that the MAbs react with specificity to the NHP-B, in both its native form and in a denatured state, enabling the application of the MAbs to several different serological formats which can be utilized to develop rapid testing methods for clinical specimens, even in field situations.

\section{MATERIALS AND METHODS}

NHP-B isolation. Since the NHP-B has not yet been succesfully cultivated in vitro, it was necessary to produce NHP-B in vivo using Litopenaeus vannamei in the laboratory in accordance with procedures by Vincent \& Lotz (2004). The NHP-B used by Vincent \& Lotz (2004) and in the present study was originally obtained from infected farmed shrimp in south Texas. Briefly, specific pathogen-free (SPF) juvenile $L$. vannamei were fed with macerated NHP-B infected HP. Small portions of the HP used for feeding were examined by conventional H\&E histology and by PCR to confirm the presence of NHP-B. The HP from freshly dead or moribund shrimp was macerated and fed to the remaining shrimp. Once the infection was established in the shrimp population, as determined by PCR analysis of fecal samples, the HP from infected, moribund shrimp were excised under aseptic conditions and used to prepare cellular suspensions which contained the bacteria. The HPs were then gently disrupted into a single cell suspension. The suspension was then either frozen in tissue culture freeze media containing 10\% dimethylsulfoxide (DMSO; ATCC, ) 90\% fetal bovine serum (FBS-Irvine Scientific) and stored in liquid nitrogen for later use, or the cells were suspended in base media (RPMI-1640 media with L-glutamine) for further purification.

NHP-B purification. Once the HPs were disrupted into a single cell suspension in RPMI base media, the cells were centrifuged at $2000 \times g$ for $15 \mathrm{~min}$, at $4^{\circ} \mathrm{C}$. The cells were suspended in lysis buffer according to the method used by Konkel et al. (1990) to extract intracellular bacteria. The cells were lysed while in suspension using phosphate buffered saline (PBS) with $0.2 \%$ Triton X-100 (Sigma), for $30 \mathrm{~min}$ at room temperature (rt). Cells were then centrifuged at $2000 \times g$ for $10 \mathrm{~min}$ at rt to pellet large cell debris. The supernatant fluid was removed and transferred to a new tube and then centrifuged at $13000 \times g$ for $30 \mathrm{~min}$ at rt. The pellet was suspended in $4 \mathrm{ml}$ PBS and then mixed with an equal volume of freon for $10 \mathrm{~min}$, according to methods described by Bonami et al. $(1990,1995,1997)$ to reduce cellular lipids, glycoproteins, and carbohydrates. The freon mixture was centrifuged again at $2000 \times g$ for $10 \mathrm{~min}$ to separate the layers. Supernatant fluid was removed and transferred to a clean tube and both the lipid layer and freon were discarded. The remaining supernatant fluid was again centrifuged at $13000 \times g$ for $30 \mathrm{~min}$ at rt. The pellet was suspended in $1 \mathrm{ml} \mathrm{PBS}$, then dispensed in $100 \mu \mathrm{l}$ aliquots and frozen at $-80^{\circ} \mathrm{C}$ for later use. A sample of the purified isolate was tested by PCR to corroborate that the sample contained NHPB. Some of the aliquots were used for transmission electron microscopy (TEM) to evaluate the purification of the resulting NHP-B suspensions.

Transmission electron microscopy. Pelleted bacteria were suspended in $200 \mu \mathrm{l} 1 \times$ TN buffer $(0.02 \mathrm{M}$ Tris$\mathrm{HCl}_{1} 0.4 \mathrm{M} \mathrm{NaCl}, \mathrm{pH} 7.4$ ) and $10 \mu \mathrm{l}$ samples were placed onto formvar-coated 200 mesh copper grids. The samples were negatively stained for 3 min with $2 \%$ phosphotungstic acid (PTA) at $\mathrm{pH} 7.0$, air dried and examined using a Phillips CM12 electron microscope.

MAb production. MAbs were prepared according to the procedure described by Poulos et al. (1999, 2001). Balbc/ByJ mice (Jackson Laboratories, Bar Harbor, ME.) were injected intraperitoneally (IP) with purified NHP-B at a $0.001 \mu \mathrm{g}$ per mouse concentration and a series of immunizations were carried out at 2 wk intervals over a $6 \mathrm{wk}$ period. The immunizations contained the purified NHP-B. Some of the purified NHP-B was denatured by boiling for $10 \mathrm{~min}$, and some was left in its native state. The resulting bacterial preparations were then pooled together and emulsified with synthetic adjuvant (MPL-TDM; RIBI Immunochem Research). Three mice were given IP 
immunizations at $2 \mathrm{wk}$ intervals in the MPL-TDM adjuvant for the first 2 immunizations. Serum from each mouse was collected and then tested for antibody production $7 \mathrm{~d}$ after the second booster immunization was administered to assess immune response of the mice to the NHP-B. Immune sera were diluted 1:1000 in PBS and tested by IHC for NHP-B detection by using Davidson's AFA fixed paraffin embedded tissue sections from NHP-B infected shrimp. The immune sera were also tested in a D-IB assay containing both native and denatured purified NHP-B. Goat anti-mouse IgG, $F\left(a b^{\prime}\right)_{2}$, gamma chain specific, alkaline phosphatase labeled secondary antibody (EY Laboratories) was used for final indirect detection. Following confirmation of positive reactions with the immune sera, a third booster immunization containing native and denatured NHP-B in PBS was given to each mouse at the $6 \mathrm{wk}$ interval, and the resulting sera were again collected and then tested on Day 2 post immunization to select the best responding animal. Starting with a 1:1000 dilution of serum in PBS, the sera were diluted 10-fold to 1:10 000 and the antibody titer was determined by using IHC and D-IB. The mouse selected for hybridoma development was chosen based upon the serum which displayed the highest titered immune response. Spleen cells obtained from the selected mouse were used in the fusion to make the hybridomas. The resulting hybridomas were cultured in selective media for $14 \mathrm{~d}$ at $37^{\circ} \mathrm{C}$, then the hybridomas were transferred into RPMI-1640 media with L-glutamine (Sigma) containing $10 \%$ FBS. On Day 10, supernatant fluid from the hybridoma cultures were reacted with both intact and denatured NHP-B samples. Several hybridomas were selected based on their response with the NHP-B in D-IB (using both native and denatured NHP-B) and IHC. The selected hybridomas were then cloned by limiting dilution (Galfre \& Milstein 1981). The limiting dilution was carried out a total of 3 times to assure the monoclonality of the MAbs. produced. Two MAbs were isotyped as IgG class 3, kappa light chain $\left(g_{3} \mathrm{k}\right)$, using a mouse monoclonal antibody isotyping kit, according to the manufacturer's protocol (Roche Molecular Biochemicals). The clones producing these antibodies, designated 3D6 and 4A2, were selected for further development. A third interesting clone was not stable in culture and it was discarded.

Dot-immunoblot assays. D-IB assays were performed according to Nadala \& Loh (2000) and Poulos et al. (2001) with some modifications. Briefly, NHP-B was loaded onto nitrocellulose plates (MAHA plates, Millipore) using $1 \mu \mathrm{l}$ per well of denatured and native sample, so that each well contained $1 \mu \mathrm{l}$ of denatured antigen at the bottom left portion of the well and $1 \mu \mathrm{l}$ of the native antigen at the top right portion of the same well. The remaining part of this assay was run according to methods previously described by Poulos et al. (1999). The membranes were blocked with $400 \mu \mathrm{l}$ per well of $2 \%$ non-fat milk (NFM), incubated with primary antibody in $100 \mu \mathrm{l}$ of hybridoma supernatant fluid for $1 \mathrm{~h}$, then washed 3 times with PBS. Goat anti-mouse IgG, F(ab') ${ }_{2}$, gamma chain specific, alkaline phosphatase labeled secondary antibody (EY Laboratories) was diluted 1:1000 in PBS + 2\% $\mathrm{NFM}$, and $100 \mu \mathrm{l}$ per well was added, for $1 \mathrm{~h}$ at rt, rinsed 3 times with PBS and the reactions were developed for 15 to 30 min using the colorimetric substrate, nitroblue tetrazolium (NBT) and bromochloroindoyl phosphate (Xphos) in a pH 9.5 buffer.

Immunohistochemistry on fixed sections. SPF Litopenaeus vannamei (Wyban 1992) were experimentally infected with NHP-B. Moribund animals were fixed with Davidson's AFA fixative for 24 to $48 \mathrm{~h}$ (Bell \& Lightner 1988). The tissues were embedded in paraffin and $4 \mu \mathrm{m}$ sections were prepared and placed onto Superfrost Plus ${ }^{\circledast}$ positively charged microscope slides (Fisher Scientific). Slides were also prepared and utilized from consecutive sections of shrimp where the NHP-B disease status of the shrimp was confirmed by characteristic lesions using routine histological methods (Lightner 1996). After heating at $65^{\circ} \mathrm{C}$ for $45 \mathrm{~min}$ to melt the paraffin, the sections were rehydrated through a series of three 5 min washes in Clear-Rite ${ }^{\circledR}$ (a xylene substitute; Richard-Allan Scientific), 95\% alcohol, $80 \%$ alcohol, $50 \%$ alcohol and 6 washes in distilled water. The sections were incubated for $5 \mathrm{~min}$ in PBS and then blocked with PBS containing $10 \%$ normal goat serum (NGS) and 2\% NFM for $15 \mathrm{~min}$ at $37^{\circ} \mathrm{C}$. Supernatant fluid was harvested from the hybridomas and centrifuged for $5 \mathrm{~min}$ at $13000 \times g$ to pellet cells, and $500 \mu \mathrm{l}$ of the supernatant fluid containing MAb was applied to the rehydrated tissue section for 30 min at rt. The MAbs were tested using NHP-B positive, as well as SPF samples. After washing in 3 changes of PBS, the sections were reacted with a goat anti-mouse IgG, $\mathrm{F}\left(\mathrm{ab}^{\prime}\right)_{2}$ antibody conjugated to alkaline phosphatase (Zymed) diluted 1:1000 in PBS+2\% $\mathrm{NFM}+10 \% \mathrm{NGS}$, for $30 \mathrm{~min}$ at rt. The reactions were then developed for 15 to 30 min using NBT and X-phos in a $\mathrm{pH} 9.5$ buffer. The sections were counterstained with Bismarck brown and dehydrated through a series of alcohol washes ending with Clear-Rite ${ }^{\circledR}$ according to the procedure described by Poulos et al. (2001). Resultant slides were cover slipped with permanent mounting medium and examined under light microscopy for the presence of a blue-black precipitate indicating a positive reaction.

MAb specificity. Pure cultures of the bacteria Aeromonas sobria, Campylobacter sp., Spiroplasma sp., Vibrio sp. (3 isolates that were used have been identified as probable $V$. harveyi), Vibrio paraheae- 
molyticus, Vibrio vulnificus, Vibrio penaecidia, and Vibrio alginolyticus were used in a D-IB assay to check for cross reactivity of the MAbs. The Vibrio sp., Aeromonas sp., and Spiroplasma sp. bacteria were all isolates from the bacterial culture collection of the Aquaculture Pathology Laboratory, University of Arizona. The Vibrio sp. and Aeromonas sp. isolates have been identified using the API-NE test strips and Gram stains to assist in the identification process. The Spiroplasma sp. and Campylobacter sp. used for cross reactivity studies in the D-IB assay were harvested from pure in vitro bacterial cultures collected, isolated in our facility, and identified through PCR and genetic sequencing at the DNA Sequencing Core facility at the University of Arizona. The IHC studies were all performed using established infected samples which were verified by ISH and characteristic lesions in routine histological methods (Lightner 1996). The bacterial cells were loaded onto the nitrocellulose plates (MAHA plates, Millipore) in the same manner as the purified NHP-B. The MAbs were also tested by IHC using confirmed cases (from the collection of Aquaculture Pathology Laboratory, University of Arizona) of shrimp infected with a rickettsia-like bacterium of shrimp, Vibrio sp., and Spiroplasma sp. (Nunan et al. 2004). Positive control samples from NHP-positive shrimp and negative control from samples of SPF shrimp were run simultaneously.

\section{RESULTS}

\section{NHP-B transmission electron microscopy}

The purified NHP-B preparations were visualized by TEM using $2 \%$ PTA as the negative stain (Fig. 1). After TEM confirmation that the purification produced a clean preparation of intact NHP bacteria, the sample was utilized as the immunogen for the preparation of the MAbs and as antigen for use in the D-IB assay.

\section{MAb production}

Previous attempts to produce MAbs to NHP using intact-native bacteria emulsified in synthetic adjuvant resulted in antibodies which reacted to the organism only in its native form, and the hybridomas were not stable. It is probable that these antibodies reacted to lipids, glycoprotiens, and/or carbohydrates present in the NHP-B cell wall (Kraus et al. 2001), since the extraction method utilized Triton X-100 to disrupt the cell walls, and is known to release lipids, carbohydrates and glycoproteins. To alleviate this problem, a freon extraction was incorporated, to remove or deplete the lipids, glycoprotiens and/or carbohydrates (Priest et al. 2001). The NHP-B were then denatured by boiling and a mixture of the native and denatured NHP-B were used for the immunization of the mice. Antibodies obtained reacted to both intact and denatured forms of the NHP-B and the resultant hybridomas tended to be very stable. Several hybridoma clones, which produced MAbs that reacted to the NHP-B in D-IB and IHC, were chosen for sub-cloning and characterization. The clones, designated 3D6 and $4 \mathrm{~A} 2$, were chosen for development. Both MAbs 3D6 and $4 \mathrm{~A} 2$ reacted in the $\mathrm{D}-\mathrm{IB}$ assay to native and denatured purified NHP-B and by IHC in the fixed tissue sections of the NHP-B infected shrimp. MAbs 3D6 and $4 \mathrm{~A} 2$ were isotyped and found to be $\operatorname{IgG}_{3}, \mathrm{k}$.

\section{Dot-immunoblot analysis}

During the initial screening process, 96 wells containing the growing hybridomas were examined against both native-intact and denatured purified NHP-B. The antibodies that did not react or reacted with only 1 of these antigenic forms were not evaluated further. Antibodies that reacted to both native and

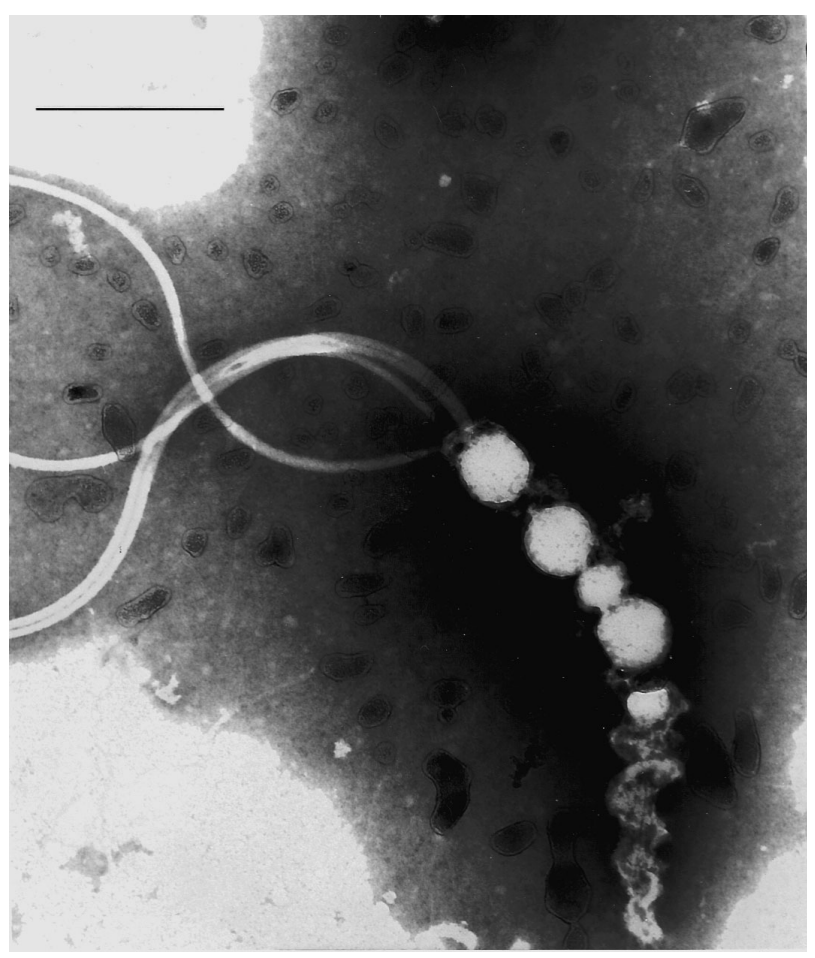

Fig. 1. Transmission electron micrograph (TEM) of purified necrotizing hepatopancreatitis bacteria (NHP-B), negatively stained with $2 \%$ phosphotungstic acid (PTA). The NHP-B helical form with 8 flagella on the basal apex as described by Lightner (1996) was the only observed organism in the TEM. Scale bar $=0.5 \mu \mathrm{m}$ 
denatured NHP-B antigens were selected for further investigation by IHC (Fig. 2). In the D-IB assay, hybridoma supernatant fluids were tested without concentration and the reactions were scored on a scale of increasing intensity $(+1$ to +4$)$. Several MAbs reacted strongly in assays against both antigens, with a grade +3 to +4 reaction (Table 1 ) .

\section{Immunohistochemistry}

IHC was performed on $4 \mu \mathrm{m}$ thick tissue sections. The disease status of infected shrimp used for these tissue sections was confirmed by demonstration of the presence or absence of characteristic lesions using routine histological methods with consecutive sections (Lightner 1996). The pattern of reactivity using the MAbs was similar to that seen using specific digoxigenin-labeled gene probes. Only areas demonstrating lesions typical of acute NHP infection were marked by the deposition of the MAb and subsequently developed with the chromogenic substrate (Fig. 3). The reactions were easily visualized using light microscopy. Several MAbs were screened in the IHC format after testing positive in the D-IB assay; however, only MAbs 3D6 and 4A2 reacted with the NHP-B infected tissue sections (Table 1). These MAbs did not react with tissue sec-
Table 1. Characteristics of selected monoclonal antibodies (MAbs) to necrotizing hepatopancreatitis bacteria (NHP-B). Immunoglobulin isotypes were determined using a dipstick mouse subtyping kit. In the dot-immunoblot (D-IB) assay, screened in the D-IB assay against both native and denatured NHP-B. MAb nere equal under both native and denatured conditions and were scored on a scale of increasing intensity $(+1$ to +4$)$. In the immunohistochemistry (IHC) assay, hybridoma supernatant fluids were tested after hybridoma cells were removed from the supernatant fluid. NA: not assessed because of lack of reactivity in IHC

\begin{tabular}{|lcccc|}
\hline $\begin{array}{l}\text { Hybridoma/MAb } \\
\text { designation }\end{array}$ & $\begin{array}{c}\text { Immunoglobulin } \\
\text { isotype }\end{array}$ & \multicolumn{2}{c|}{$\begin{array}{c}\text { Reactivity to NHP } \\
\text { in dot immunoblot } \\
\text { Native }\end{array}$} & $\begin{array}{c}\text { Reactivity to } \\
\text { DHP in IHC }\end{array}$ \\
\hline 3D6 & IgG $\left(g_{3} \mathrm{k}\right)$ & +4 & +4 & +4 \\
$4 \mathrm{~A} 2$ & $\mathrm{IgG}\left(\mathrm{g}_{3} \mathrm{k}\right)$ & +3 & +3 & +4 \\
$2 \mathrm{C} 1$ & $\mathrm{NA}$ & +2 & +2 & 0 \\
$3 \mathrm{~B} 2$ & $\mathrm{NA}$ & +4 & +2 & 0 \\
$3 \mathrm{~B} 4$ & $\mathrm{NA}$ & +3 & +1 & 0 \\
$3 \mathrm{~B} 6$ & $\mathrm{NA}$ & +4 & +2 & 0 \\
$4 \mathrm{C} 1$ & $\mathrm{NA}$ & +4 & 0 & 0 \\
\hline
\end{tabular}

tions prepared from SPF shrimp (Table 2). Those MAbs which did not react in the IHC were not further characterized (Table 1). The IHC procedure took less than $4 \mathrm{~h}$ to complete once tissue was sectioned onto microscope slides. The time for fixation, paraffin embedding and sectioning of the tissues, however, required an additional $48 \mathrm{~h}$ prior to the reaction with MAb.

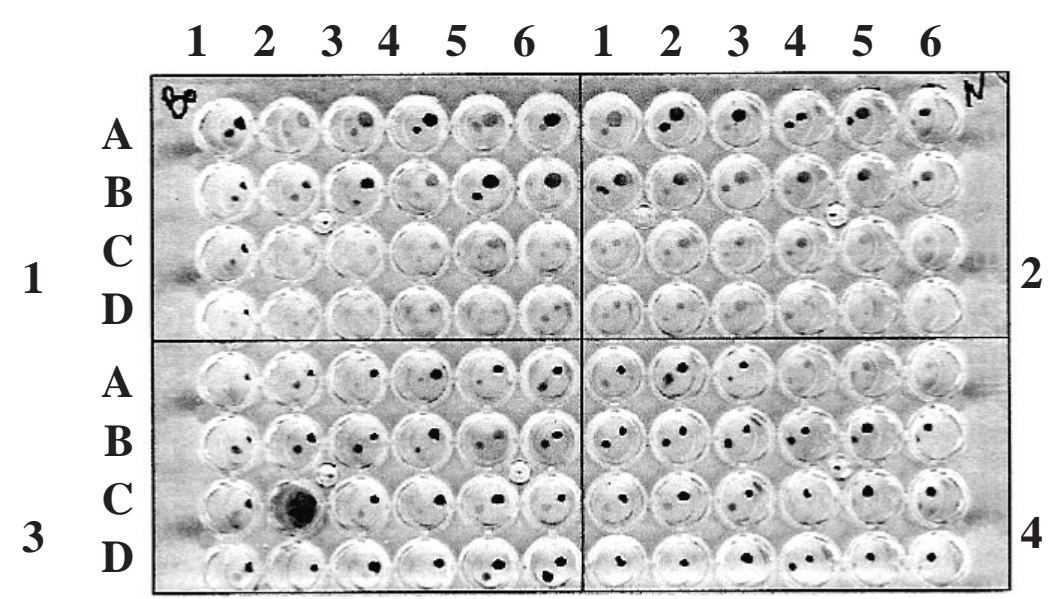

Fig. 2. Dot-immunoblot of primary screening to select for hybridomas reactive to NHP-B. Four 24-well plates were assayed on a 96 -well nitrocellulose plate. Each quadrant of the 96-well plate corresponds to a 24 -well hybridoma plate. The bottom left of each well contains denatured purified NHP-B, while the top right of each well contains native purified NHP-B. Cell selections were made based on the reaction to both denatured and native samples

\section{MAb specificity}

Several preparations of bacterial isolates, including a rickettsia-like bacterium from penaeid shrimp, Aeromonas sobria, Campylobacter sp., Spiroplasma sp., Vibrio sp. (3 isolates that were used have been identified as probable $V$. harveyi), Vibrio paraheaemolyticus, Vibrio vulnificus, Vibrio penaecidia, and Vibrio alginolyticus, were tested. Aeromonas sp., Vibrio sp., Campylobacter sp. and Spiroplasma sp. were screened in DIB for cross reactivity. In the D-IB assay, the MAbs demonstrated no reactivity to pure cultures of these bacteria, in either native or denatured states (Table 2). Likewise, in the D-IB assay the MAbs did not react to lysed HP suspensions from SPF (uninfected) shrimp, while MAbs reacted positively to the native and denatured NHP-B when screened (Table 2). Some species of interest could not be tested for cross reactivity by DIB since pure cultures are not available. Thus, the MAbs were screened by IHC 

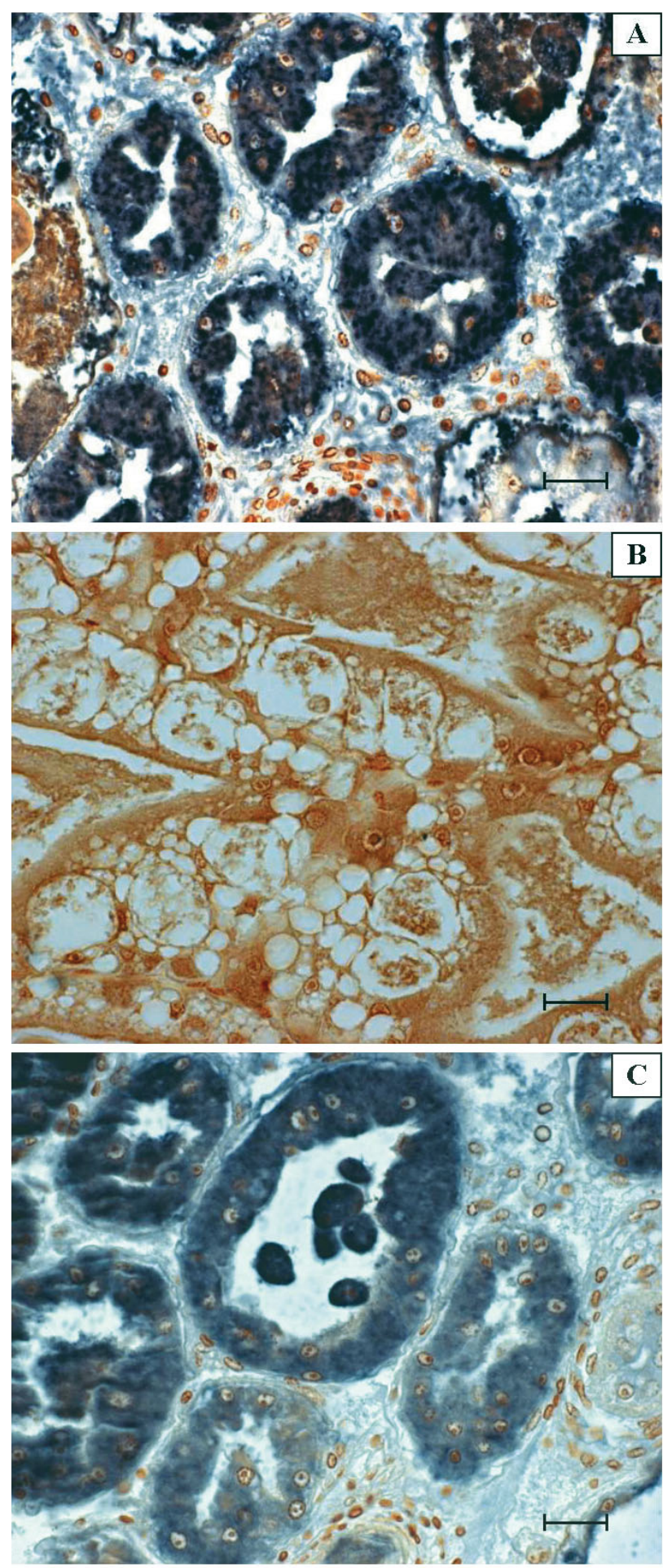

Fig. 3. Immunohistochemistry using Davidson's AFA fixed tissue sections from shrimp infected with NHP-B. (A) Reaction of MAb 4A2 with NHP-B infected hepatopancreas (HP) tissue. The staining pattern has a mottled appearance. (B) Specific pathogen-free negative control HP tissue, in which both antibodies were pooled and placed on the section. (C) The reaction of MAb 3D6 with NHP-B infected HP tissue has a homogeneous staining pattern. Scale bars $=20 \mu \mathrm{m}$
Table 2. Specificity of the anti-NHP MAbs (3D6 and 4A2) against purified bacterial preparations as determined by D-IB or IHC assays using unconcentrated supernatant fluids, with hybridoma cells removed. Reactions were scored on a scale of increasing intensity ( +1 to $+4,0=$ negative reaction). $\mathrm{NT}=$ not tested because unavailable. SPF: specific pathogen-free

\begin{tabular}{|lcccc|}
\hline \multirow{2}{*}{ Bacteria } & \multicolumn{2}{c}{ D-IB } & \multicolumn{2}{c|}{ IHC } \\
& 3D6 & $4 \mathrm{~A} 2$ & $3 \mathrm{D} 6$ & $4 \mathrm{~A} 2$ \\
\hline SPF & 0 & 0 & 0 & 0 \\
NHP bacteria & +4 & +4 & +4 & +4 \\
Campylobacter sp. & 0 & 0 & 0 & 0 \\
Rickettsia-like bacteria & $\mathrm{NT}$ & $\mathrm{NT}$ & 0 & 0 \\
Spiroplasma sp. & 0 & 0 & 0 & 0 \\
Vibrio sp. & 0 & 0 & 0 & 0 \\
Aeromonas sp. & 0 & 0 & $\mathrm{NT}$ & $\mathrm{NT}$ \\
& & & & \\
\hline
\end{tabular}

using tissues from shrimp infected with these bacteria. Shrimp that were confirmed previously by ISH with specific probes for the rickettsia-like bacteria, Spiroplasma sp., Vibrio sp., and negative control SPF samples were shown to be negative (Table 2). The IHC using NHP-B infected tissue sections was positive with both MAbs.

\section{DISCUSSION}

The purpose of this research was to develop MAbs to NHP-B and to test them for specificity to NHP-B using different assay formats. A strategy was chosen for the immunization of the mice to obtain MAbs that would react against both intact and denatured proteins of the bacteria. The rationale for obtaining such MAbs was that they could then be utilized for rapid diagnosis of NHP in clinical samples. The hybridomas were initially screened using a D-IB assay that incorporated both native and denatured NHP-B antigens. This method and others similar to it have been described previously (Poulos et al. 1999, Nadala \& Loh 2000). The MAbs chosen by the D-IB method were then screened by IHC to select those MAbs which could detect NHP-B proteins in the tissue of shrimp after they had been fixed and denatured. The MAbs were screened for cross reactivity to other bacteria that may infect shrimp by using pure cultures in D-IB assays and/or by performing IHC on infected tissue sections. The organisms, including a rickettsia-like bacteria of shrimp, Vibrio sp., Aeromonas sp., Campylobacter sp., and Spiroplasma sp., all tested negative using MAbs 3D6 and $4 \mathrm{~A} 2$, indicating strong specificity of the MAbs for the NHP-B.

The bacteria selected to screen the MAbs for specificity were chosen for a variety of reasons. The rickettsia-like bacteria of shrimp was tested for cross reac- 
tivity to the MAbs because, like the NHP-B, it is also an intracellular bacteria that infects penaid shrimp. The NHP-B was originally described as a rickettsia-like bacterium (Loy et al. 1996) that infected the HP of penaid shrimp, making this organism a candidate for cross reactivity. The Vibrio sp. was selected for specificity testing because Vibrio spp. are part of the normal flora as well as being opportunistic pathogens of shrimp that have been associated with simultaneous infections with NHP-B. The Campylobacter sp. was chosen because it is an intracellular bacterium that possesses flagella which could have antigens similar to those on the flagella of the NHP-B. The Spiroplasma sp. may be present in cultured shrimp during the same seasons and in the same geographic regions where NHP-B occurs (Nunan et al. 2004). The results after testing demonstrated specificity of the MAbs 3D6 and $4 \mathrm{~A} 2$ to the NHP-B.

Although several MAbs were identified for further testing, only 2 (3D6 and 4A2) were chosen for development because the hybridomas producing these MAbs proved to be highly stable in culture. Both 3D6 and $4 \mathrm{~A} 2$ were isotyped and found to be $\operatorname{IgG}\left(\mathrm{g}_{3} \mathrm{k}\right)$. Interestingly, IgG $\left(\mathrm{g}_{3} \mathrm{k}\right)$ isotypes tend to be prevalent in production of MAbs derived from enteric proteins, and the NHP-B is an enteric pathogen of penaid shrimp. The isotype $\operatorname{IgG}\left(\mathrm{g}_{3} \mathrm{k}\right)$ is usually derived from stable hybridomas and tends to react as a strong antibody. Additionally, IgG $\left(\mathrm{g}_{3} \mathrm{k}\right)$ isotypes are easily purified, requiring very mild conditions, which makes them less vulnerable to denaturation resulting in highly desirable antibodies for use in diagnostic assays.

The development of simple, sensitive and rapid assay formats for the detection of shrimp diseases is a continuing goal. Although the use of gene probes and DNA amplification techniques have provided valuable testing formats, the technology is generally expensive, highly technical, not rapid, and not amenable to field conditions. The use of antibodies for the detection of shrimp diseases as an alternative to gene probes and other methods has been slow to progress because of the difficulties associated with their production. This has been primarily due to the limited amounts of purified antigen available for immunization and testing, as well as the amount of time typically required to develop MAbs. However, despite these problems, MAbs are being developed by different laboratories to various penaid pathogens because of the advantages they offer over methods.

The antibody testing formats used in this study (IHC and D-IB) are both more rapid and simpler to perform than most molecular assays. The D-IB test as described here was sensitive enough to detect NHP-B in clinical shrimp specimens using a direct detection method. Likewise, once tissue sections are prepared, the IHC method was relatively easy to perform, rapid, and it required no additional equipment or specialized training. The IHC test format was chosen for study initially because of the large number of specimens received at this laboratory that are fixed in Davidson's AFA. This method of sample preservation is widely used in the shrimp culture industry and is relatively easy to perform. If histological services are accessible to the farmer, or field diagnostic laboratory, then the antibody method described here provides a level of specificity that standard histology cannot. Furthermore, IHC is more rapid than ISH with gene probes. Interpreting the IHC reactions requires only the use of a light microscope and minimal training in the determination of a positive reaction. IHC can be a valuable adjunct to normal histopathology when definitive pathogen confirmation is required.

The primary drawback to the IHC method is that it is a lethal method which requires that the shrimp be sacrificed to be tested. Work is continuing to determine alternative types of specimens which can be used for detection of this organism in clinical samples, especially using non-lethal means (e.g. for testing valuable brood stock).

In summary, the MAbs described here were specific, as well as sensitive, for the detection of NHP. These MAbs may be utilized in a variety of formats and can be applied to different methods of diagnostics, especially since more than $1 \mathrm{MAb}$ is available. The incorporation of these MAbs in a diagnostic kit would provide a rapid and simple detection method for NHP, which should prove useful to the shrimp culture industry.

Acknowledgements. Support for this research was provided by the Gulf Coast Research Laboratory Consortium Marine Shrimp Farming Program, CSREES, under grant 2002-3880801345 and a special grant from the National Fishery Institute. The authors would like to thank Rita M. Redman for histological sectioning, Linda M. Nunan and Bonnie T. Poulos for their technical assistance.

\section{LITERATURE CITED}

Aguirre-Guzmán G, Ascencio Valle F (2000) Infectious disease in shrimp species with aquaculture potential. In: Pandalai SG (ed) Recent research developments in microbiology, Vol 4. Research Signpost, Kerala, p 333-348

Bangs Laboratories Tech Notes (1999) Beads above the rest. Technote \#303 Lateral flow tests (p 1-6) and Technote \#201 Working with microspheres (p 1-16) (available at: www.bangslab.com)

Bell TA, Lightner DV (1988) A handbook of normal shrimp histology. Special Publication No. 1. World Aquaculture Society, Baton Rouge, LA

Bonami JR, Trumper B, Mari J, Brehelin M, Lightner DV (1990) Purification and characterization of the infectious hypodermal and hematopoietic necrosis virus of penaeid shrimps. J Gen Virol 71:2657-2664 
Bonami JR, Mari J, Poulos BT, Lightner DV (1995) Characterization of hepatopancreatic parvo-like virus, a second unusual parvovirus pathogenic for penaeid shrimps. J Gen Virol 76:813-817

Bonami JR, Hasson KW, Mari J, Poulos BT, Lightner DV (1997) Taura syndrome of marine penaeid shrimp: characterization of the viral agent. J Gen Virol 78:313-319

Frelier PF, Loy K, Kruppenbauch B (1992) Transmission of necrotizing hepatopancreatitis in (Pennaus vannamei). J Invertebr Pathol 61:44-48

Galfre G, Milstein C (1981) Preparation of monoclonal antibodies: strategies and procedures. Methods Enzymol 73B:3-46

Konkel M, Babakhani F, Joens LA (1990) Invasion-related antigens of Campylobacter jejuni. J Infectious Dis 162: 888-895

Kraus I, Eickmann M, Kiermayer S, Scheffczik H, Fleuss M, Richt J, Garten W (2001) Open reading frame III of Borna Disease Virus encodes a nonglycosylated matrix protein. J Virol 75:12098-12104

Lightner DV (1996) A handbook of shrimp pathology and diagnostic procedures for diseases of cultured penaeid shrimp. World Aquaculture Society, Baton Rouge, LA

Loy JK, Dewhirst FE, Weber W, Frelier PF, Garbar TL, Tasca SI, Templeton JW (1996) Molecular phylogeny and in-situ detection of the etiologic agent of necritotizing hepatopancreatitis in shrimp. Appl Environ Microbiol 62(9):3439-3445

Nadala ECB, Loh PC (2000) Dot-blot nitrocellulose enzyme immunoassays for the detection of white-spot virus and yellow-head virus of penaeid shrimp. J Virol Methods 84: 175-179

Nunan LM, Pantoja C, Aranguran F, Lightner DV (2004) Characterization of a novel spiroplasma to Penaeus van-

Editorial responsibility: Timothy Flegel, Bangkok, Thailand namei and molecular methods for the detection of the organism. In: Parsons GJ (ed) Book of abstracts. World Aquaculture Society, Honolulu, Hawaii, March 1-5, 2004. World Aquaculture Society, Baton Rouge, LA, p 216 (Abstract)

Pantoja CR, Lightner DV (2003) Necrotizing hepatopanceatitis (NHP): a review of diagnostic methods and geographic distribution. In: Parsons GJ (ed) Book of abstracts. World Aquaculture Society, Salvadore, Brazil, May 19-23, 2003. World Aquaculture Society, Baton Rouge, LA, p 550 (Abstract)

Poulos BT, Kibler R, Bradley-Dunlop D, Mohney LL, Lightner DV (1999) Production and use of antibodies for the detection of Taura syndrome virus in penaeid shrimp. Dis Aquat Org 37:99-106

Poulos BT, Pantoja CR, Bradley-Dunlop D, Aguilar J, Lightner DV (2001) Development and application of monoclonal antibodies for the detection of white spot syndrome virus of penaeid shrimp. Dis Aquat Org 47:13-23

Priest J, Long-Ti X, Arrowood M, Lammie P (2001) The immunodominant $17-\mathrm{kDa}$ antigen from Cryptosporidium parvum is glycosylphosphatidylinositol-anchored. Mol Biochem Parasitol 113:117-126

Vincent AG, Lotz JM (2004) Experimental infection of Litopenaeus vannamei by necrotizing hepatopancreatitis (NHP) via per os and injection exposure. In: Parsons GJ (ed) Book of abstracts. World Aquaculture Society, Honolulu, Hawaii, March 1-5, 2004. World Aquaculture Society, Baton Rouge, LA, p 1116 (Abstract)

Wyban JA (1992) Selective breeding of specific pathogen-free (SPF) shrimp for high health and increased growth. In: Fulks W, Main KL (eds) Diseases of cultured penaeid shrimp in Asia and the United States. The Oceanic Institute, Honolulu, HI, p 257-268

Submitted: February 4, 2004; Accepted: March 24, 2004

Proofs received from author(s): August 17, 2004 